\title{
Os Congressos de Leitura [COLEs] e a crise de leitura, então e agora
}

\section{The Reading Conferences of Brazil [COLEs] an the crisis of reading, now and then}

https://doi.org/10.34112/2317-0972a2016v34n67p27-38

Regina ZiLbERMAN ${ }^{1}$

Resumo: Nos anos 1980, por ocasião dos primeiros Congressos de Leitura (COLEs) e da fundação da Associação de Leitura do Brasil, o debate relativo à(s) crise(s) de leitura apoiava-se em concepções de livro, literatura e leitor articuladas entre si e que privilegiavam obras impressas e canônicas. Aquelas concepções, no contexto das mudanças ocorridas nas últimas décadas, talvez não mais se sustentem, indicando que o conceito de leitura, ele mesmo, encontra-se em crise, o que implica a necessidade de propor políticas de formação do leitor que levem em conta a situação diferenciada experimentada no novo milênio.

PALAVRAS-CHAVE: Livro; literatura; leitor; leitura.

ABStract: In the 1980s, during the first Reading Conferences of Brazil [COLE] and the founding of the Brazilian Reading Association [ALB], the debate on the crisis of reading was based on the ideas of book, literature and reader as articulated with each other, favoring printed and canonical works. In the context of the changes in recent decades, those concepts may no longer be maintained, indicating that the concept of reading itself is in crisis, which implies the need to propose public policies that take into account the different situation experienced in the new millennium.

KEYWORDS: Book; literature; reader; reading.

1. Universidade Federal do Rio Grande do Sul, Porto Alegre, RS, Brasil. 
Os Congressos de Leitura [COLEs] e a crise de leitura, então e agora

Nada do que foi será

De novo do jeito que já foi um dia

Tudo passa

Tudo sempre passará

Tudo que se vê não é

Igual ao que a gente

Viu há um segundo

Tudo muda o tempo todo

No mundo

Lulu Santos, Como uma Onda

Foi por volta das décadas de 1960 e 1970 que a leitura entrou no radar dos pesquisadores, educadores e formuladores de políticas públicas. De uma parte, nações que se emancipavam do jugo colonial ou que almejavam reduzir diferenças sociais propunham métodos de alfabetização que alavancassem o crescimento e garantissem a autonomia econômica e política (GRAFF, 1981; KOZOL, 1978; OXENHAM, 1980); de outra, pensadores e professores deparavam-se com a ascensão dos mass media que, aparentemente, afastavam os estudantes dos livros, deixando-os à mercê da cultura da imagem e da voz (HOGGART, 1977; LEAVIS, 1979).

No mesmo período, o impresso e o livro experimentavam sua idade de ouro. Assim, propor uma política de leitura correspondia a estimular a decodificação, entendimento e interpretação de textos escritos. A leitura podia estar em crise por falta de indivíduos letrados ou por excesso de consumo da indústria cultural, mas a solução para o problema decorria da possibilidade de dar o acesso ao universo do livro ou do suporte impresso.

Por sua vez. o livro de que se falava era o que carregava uma obra literária, em que estivesse presente a ficção e a fantasia, ingredientes fundamentais da vida humana plena. Em 1972, em ensaio que se tornou paradigmático, "A literatura e a formação do homem", Antonio Candido destaca a função humanizadora da literatura, ao mesmo tempo em que sublinha "a necessidade universal de ficção e de fantasia", colocada ao nível das "necessidades mais elementares" do ser humano (CANDIDO, 2002, p. 80).

Assim, leitura, livro impresso e literatura constituíam um tripé fortemente articulado, de modo que fomentar qualquer um de seus apoios significava simultaneamente favorecer os outros dois. Talvez tenha sido rompida essa unidade, em 
decorrência do passar do tempo e das transformações socioculturais ocorridas no período, com consequências que atingem as propostas de valorização de qualquer uma das escoras daquele tripé.

O LIVRO IMPRESSO

Em poucas décadas, o livro parece ter passado do céu para o inferno, conforme um processo que está longe de ter sido concluído. Se, em 1980, por ocasião da fundação da Associação de Leitura do Brasil e dos primeiros Congressos de Leitura, experimentava-se a idade de ouro do livro, entendido como o objeto que não podia faltar nas bibliotecas públicas e escolares, devia ser consumido dentro e fora da sala de aula, e não se confundia com seu parente próximo, o didático, hoje presencia-se à sua crise de identidade.

Em primeiro lugar, ele passou a vir acompanhado de um adjetivo que explicita sua forma: é livro impresso, digital, virtual. Além disso, pode ser até ignorado, ainda que seus surrogates procurem lembrá-lo de alguma maneira, seja pela nomeação escolhida - e-books, termo em inglês também adotado no Brasil -, seja por seu formato. Assim, plataformas e aplicativos capacitados a transmitir seu conteúdo, como e-readers e tablets, guardam o formato retangular do livro, bem como suas dimensões. O Kindle, por exemplo, com 11,9 cm de largura e 16,9 cm de altura, e o Kobo, com 11,4 $\mathrm{cm}$ de largura e 16,5 de altura, adotam medidas próximas do padrão do livro impresso $-14 \mathrm{~cm} \mathrm{X} 21 \mathrm{~cm}$ - e quase idênticas às do pocket book, com seus usuais $11 \mathrm{~cm} \mathrm{X16} \mathrm{cm.}$

Por último, perdeu a aura de que se revestia, ao ser designado como suporte, de existência transitória e eventualmente com prazo de vencimento estabelecido. Não são poucos os pensadores que debatem se o seu final está próximo ou ainda é longínquo, mas, de um modo ou de outro, parece haver consenso de que dificilmente voltará a gozar da unanimidade e da hegemonia, inquestionáveis até poucas décadas atrás (DARNTON, 2010; ECO; CARRIÈRE, 2010; ECO, 2011; NUNBERG, 1998; SCHNAPP; BATTLES, 2014).

\section{A literatura}

Também a literatura implodiu, e talvez o fenômeno tenha sido ainda mais impressionante. 
Tal como o livro, a literatura vinha constituindo um conceito e uma produção relativamente estável desde o final da Idade Média. E não é mera coincidência que os dois - livro manufaturado de modo mecânico e em escala industrial, de uma parte, e a literatura, designando o conteúdo disseminado por aquele objeto - tenham aparecido, enquanto conceito e enquanto prática, quase simultaneamente. Com efeito, até então, as produções com a palavra, fossem as manifestações orais ou escritas, eram conhecidas como "poesia", e esse termo não estabelecia distinções entre os modos como que se dava a transmissão, menos ainda se preocupava com sua conservação, dependente sobretudo da memória de seus criadores ou da audiência.

Não que essas manifestações tivessem desaparecido; porém, aquelas em que não era reconhecido o mérito de serem registradas em algum suporte material, acabavam por receber designação que, de certo modo, as rebaixava. As expressões "literatura popular" ou "literatura oral" são exemplos da operação de adjetivação que confere ao substantivo livre de atributos qualificativos o status de pureza, autenticidade e superioridade. Competiu ao livro acolher a matéria considerada mais elevada; e, como apresentava maior durabilidade que as demais formas de registro - o folheto, o cartaz, o jornal, o almanaque - revestiu-se de primazia similar, caminhando, assim, na direção da aura que o acompanhou por séculos e que, nos tempos atuais, vê ser disputada por outras ferramentas de transmissão da escrita.

No entanto, a literatura enquanto conteúdo autossuficiente e autorregulado só existe conceitualmente, enquanto um termo genérico que abriga manifestações concretas, como poemas, contos, romances, peças teatrais. Por sua vez, a vitalidade desses gêneros depende de eles circularem e serem acolhidos, respondendo, positivamente ou não, aos anseios dos distintos consumidores. Enquanto esses pareciam constituir uma unidade, não era difícil falar em leitor enquanto um ser homogêneo, contínuo e, de certo modo, imutável.

Aquela unidade, formada por um produto e um mercado, pôde subsistir enquanto literatura e livro puderam contar com um intermediário confiável e universal - a escola, que alfabetizava segundo um padrão linguístico, extraído, não por coincidência, das obras consagradas do passado. A escola garantiu a consolidação de um cânone, nacional e internacional, que difundiu por meio de seus aparelhos e de profissionais habilitados ao exercício de tal encargo. E obteve êxito, porque seus destinatários pertenciam à classe social de onde provinham seus criadores - a burguesia, que identificava na educação um instrumento competente para veiculação de seus valores e cultura. 
Esse sólido edifício perdurou por um bom tempo, mas suas bases começaram a ser corroídas pelo andamento da própria sociedade burguesa que, focada no êxito econômico, precisou alargar suas fronteiras. De uma parte, multiplicou os produtos literários a serem oferecidos, dando margem ao aparecimento, consolidação e expansão da chamada indústria cultural e, no caso específico de que se fala, da literatura de massa. De outra parte, ambicionou ampliar as fronteiras de sua clientela, induzindo novos contingentes de consumidores a absorvê-la, educando-os para atingir tal finalidade. Esses, porém, dispunham de suas próprias expressões culturais, que exigiam reconhecimento, mas que não coincidiam com o paradigma vigente. Estilhaçou-se a literatura em matérias e gêneros diversos, aos quais se agregam aqueles provenientes da nova condição propiciada pela difusão do mundo digital.

Assim, aos gêneros literários tradicionais, adicionam-se tipos de textos que não podem ser descritos pelos mecanismos usuais da história ou da teoria da literatura, sejam eles performances, grafites, novelas gráficas, blogues, emails, postagens. Como organizar, em um único vocábulo, o que se vale da palavra, mas não só, recorrendo ao corpo, ao som ou à imagem; e aparece em livros, mas também em muros, sites, gestos, sendo que esses prescindem daquele.

Que o conceito de literatura parece insuficiente para dar conta das produções com a palavra que pretendem ser julgadas arte, sugerem-no os Parâmetros Curriculares Nacionais (PCNs). Nesses, a literatura é traduzida por textos literários, os quais, embora preservados enquanto "uma forma peculiar de representação e estilo em que predominam a força criativa da imaginação e a intenção estética” (BRASIL, 1998, p. 26), são entendidos como um gênero de discurso, ao lado de, entre outras expressões linguísticas, cartas, relatos biográficos, peças publicitárias, matérias jornalísticas (a que se poderiam acrescentar, contemporaneamente, emails, blogues ou postagens em redes sociais). Corolário dos PCNs são as provas do Exame Nacional do Ensino Médio (ENEM), cujos enunciados invocam, entre outras possibilidades, tiras, cartuns, letras de música, atestando, pois, a profunda alteração de que se fala.

O exemplo a seguir, reproduzindo a questão 96, do Caderno Amarelo, de 2015, parece validar o que se observa em relação ao conceito e a prática da literatura, uma vez que essa é representada pelo rap, gênero simultaneamente literário e musical, a que se agrega a dança e a performance:

O rap, palavra formada pelas iniciais de rhythm and poetry (ritmo e poesia), junto com as linguagens da dança (o break dancing), e das artes plásticas (o grafite), seria 
difundido, para além dos guetos, com o nome de cultura hip hop. O break dancing surge como uma dança de rua. O grafite nasce de assinaturas inscritas pelos jovens com sprays nos muros, trens e estações de metrô de Nova York. As linguagens do rap, do break dancing e do grafite se tornaram os pilares da cultura hip hop.

DAYRELL, J. A música entra em cena: o rap e o funk na socialização da juventude. Belo Horizonte: UFMG, 2005 (adaptado).

Entre as manifestações da cultura hip hop apontadas no texto, o break se caracteriza como um tipo de dança que representa aspectos contemporâneos por meio de movimentos

A. retilíneos, como crítica aos indivíduos alienados.

B. improvisados, como expressão da dinâmica da vida urbana.

C. suaves, como sinônimo da rotina dos espaços públicos.

D. ritmados pela sola dos sapatos, como símbolo de protesto.

E. cadenciados, como contestação às rápidas mudanças culturais. ${ }^{2}$

A escolha do rap como objeto da questão não é ocasional, o que corrobora a asserção de que a noção tradicional de literatura, vinculada à escrita e ao cânone estabelecido pela história da literatura e pela escola, não dá conta do que circula como matéria de leitura e expressão em classes sociais, grupos e camadas urbanas não assimiláveis à burguesia ou à classe média. E que constituem o contingente que, majoritariamente, frequenta a escola e prepara-se para o acesso ao ensino superior. Assim, o tema retorna na questão 122, do Caderno Amarelo, por ocasião da segunda aplicação da prova, em dezembro de 2015:

O rap constitui-se em uma expressão artística por meio da qual os MCs relatam poeticamente a condição social em que vivem e retratam suas experiências cotidianas.

SOUZA, J.; FIALHO, V. M.; ARALDI, J. Hip hop: da rua para a escola. Porto Alegre: Sulina, 2008.

O "relato poético" é uma característica fundamental desse gênero musical, em que $o$

A. MC canta de forma melodiosa as letras, que retratam a complexa realidade em que se encontra.

2. Material disponível em: <http://vestibular.uol.com.br/provas-e-correcoes/2015/acompanhe-a-correcaocomentada-do-enem-2015/index.htm?next=0001H9U8N\#amarela-2-96>. Acesso em: 02 jul 2016. A resposta correta está assinalada em negrito. 
B. rap se limita a usar sons eletrônicos nas músicas, que seriam responsáveis por retratar a realidade da periferia.

C. rap se caracteriza pela proximidade das notas na melodia, em que a letra é mais recitada do que cantada, como em uma poesia.

D. MC canta enquanto outros músicos o acompanham com instrumentos, tais como o contrabaixo elétrico e o teclado.

E. MC canta poemas amplamente conhecidos, fundamentando sua atuação na memorização de suas letras. ${ }^{3}$

Tanto quanto o livro, seu companheiro de viagem, a literatura, material original daquele, perde a aura e a unanimidade, evidenciando-se um conceito abstrato, indiferente aos acontecimentos culturais e sociais de que se nutre.

\section{A Leitura}

Em um cenário em que o livro perdeu a uniformidade, e a literatura, a unidade, a leitura não poderia permanecer incólume. Processo calcado no reconhecimento de uma alteridade que aparece sob a forma de texto a decifrar, a leitura requer uma metodologia que faculte seu exercício - um letramento. Esse termo, derivado da letra a que dá acesso, mostrou-se útil enquanto leitura equivaleu, de certo modo em regime de exclusividade, à decodificação da escrita. Esse procedimento, porém, revelou-se limitado, quando a expressão verbal foi substituída por outras manifestações de linguagem - a corporal ou a digital, por exemplo. O vocábulo, tal como ocorreu com o livro, viu-se obrigado a aceitar a companhia de adjetivos que o particularizam, seja quando se depara com discursos, como o que se refere ao "letramento literário", seja quando aponta para práticas advindas do desenvolvimento tecnológico, como o que diz respeito ao "letramento digital".

O problema, porém, não se situa na heterogeneidade que a leitura passou a apresentar, quando proliferaram os procedimentos a que ela se refere. E sim na situação dos leitores, cuja diversidade não pode ser ignorada. Em consequência, não se trata apenas de valorizar e difundir práticas de leitura, mas de refletir sobre os indivíduos a quem elas se dirigem. Como se observou, foi possível, por algum tempo, considerar o

3. Material disponível em: <http://download.inep.gov.br/educacao_basica/enem/provas/2015/CAD _ ENEM_2015_2aAPLICACAO_DIA_02_05_AMARELO.pdf $>$. Acesso em: 02 jul 2016. A resposta correta está assinalada em negrito. 
leitor uma entidade genérica, mesmo quando levadas em conta as diferenças de gênero, em pesquisas sobre a leitura. Não que não se possa conferir universalidade ao ato de ler, atitude a que os seres humanos estão aptos e que se concretiza em determinadas circunstâncias, em resposta aos estímulos de um objeto a que podemos chamar de texto (ISER, 1974; ISER, 1996-99; ZILBERMAN, 2001; ZILBERMAN, 2015).

Entretanto, a reflexão sobre o leitor não se limita a entendê-lo enquanto o sujeito habilitado à decodificação e à interpretação de sinais, a que confere um sentido sob a forma de linguagem (BENJAMIN, 1992), ainda que esse comportamento heurístico não tenha perdido a validade. Cabe também entendê-lo enquanto diversidade, levando em conta os elementos - por exemplo, étnicos, sociais, de gênero - de que se compõe.

Por outro lado, pensar o leitor/a leitora em sua diversidade requer igualmente ultrapassar a identificação das diferenças de gênero, classe social, etnia, formação ou profissionalização, a que se somam os fatores históricos que intervêm em sua composição. É que, em um país de tantas desigualdades como o Brasil, agudizam-se os desníveis entre leitores pertencentes a grupos similares - etários, escolares, regionais -, impedindo universalizações. Além disso, cada leitor/a entende-se enquanto único e insubstituível, acima de tudo um sujeito, emergindo, dessa maneira, vontades ou não de prática de leitura. Tais multiplicidade e disparidades dificultam a formulação de uma concepção homogênea sobre os termos que pertencem à equação ato de ler, leitor/a, leitura. Em razão disso, uma questão se agrega às anteriores, decorrente da relação entre os sujeitos leitores e a leitura: o fato de que boa parte deles parece não se interessar em praticá-la na forma convencional com que ela se oferece nos espaços em que circula.

Como se observou, o rompimento da unidade da literatura resultou, em grande parte, da ascensão de um contingente ativo de produtores e de público que dispõem de seus canais de criação e recepção, não oficialmente reconhecidos pelos aparelhos educacionais e culturais. Por sua vez, esses buscam atraí-los, conforme sugerem exemplos retirados das provas do ENEM de 2015. Exemplifica-o a questão 107, em que se verifica o empenho em aplicar uma regra a um enunciado oral que, reproduzido pela escrita, foge ao padrão culto da língua portuguesa:

\section{Assum preto}

Tudo em vorta é só beleza

Sol de abril e a mata em frô 
Mas assum preto, cego dos óio

Num vendo a luz, ai, canta de dor

Tarvez por ignorança

Ou mardade das pió

Furaro os óio do assum preto

Pra ele assim, ai, cantá mió

Assum preto veve sorto

Mas num pode avuá

Mil veiz a sina de uma gaiola

Desde que o céu, ai, pudesse oiá

GONZAGA, L.; TEIXEIRA, H. Disponível em: http://www.luizgonzaga.mus.br. Acesso em: 30 jul. 2012 (fragmento).

As marcas da variedade regional registradas pelos compositores de Assum preto resultam da aplicação de um conjunto de princípios ou regras gerais que alteram a pronúncia, a morfologia, a sintaxe ou o léxico. No texto, é resultado de uma mesma regra a
A. pronúncia das palavras "vorta" e "veve".
B. pronúncia das palavras "tarvez" e "sorto".
C. flexão verbal encontrada em "furaro" e "cantá".
D. redundância nas expressões "cego dos óio" e "mata em frô".
E. pronúncia das palavras "ignorança" e "avuá".

Também as propostas expostas no projeto da Base Nacional Comum Curricular (BNCC) procuram integrar a produção que excede o canônico e o oficial, de modo que o "campo literário" passa a corresponder ao

[...] campo de atuação que diz respeito à participação em situações de leitura/escuta, produção oral/ sinalizada/escrita, na criação e fruição de produções literárias, representativas da diversidade cultural e linguística, que favoreçam experiências estéticas. (BRASIL, 2016, p. 90).

4. <http://download.inep.gov.br/educacao_basica/enem/provas/2015/CAD_ENEM\%202015_DIA\%20 2_o5_AMARELO.pdf $>$. Acesso em: 02 jul 2016. A resposta correta está assinalada em negrito. 
Na sequência, são apresentadas enquanto gêneros textuais exemplares do campo literário as produções como animês, autobiografias, contos/histórias, cordéis, crônicas, diários, fábulas, fanfics, HQs, lendas, mangás, minicontos, mitos, narrativas de aventura, narrativas de mistério e suspense, novelas, peças teatrais, poemas de forma fixa, poemas de verso livre, poemas visuais, quadras, romances, tirinhas, sinalizando o cuidado em abarcar uma totalidade, atualmente perdida, que já pertenceu ao conceito de literatura e que justificava a leitura.

Tais iniciativas parecem ter, portanto, o intuito de domesticar e aclimatar uma produção e uma recepção que, em muitos casos, não almeja ser integrada ao cânone, não apenas porque esse não lhe diz respeito, mas, e sobretudo, porque ele priva aquelas expressões do teor de resistência que elas podem conter.

Referir-se à leitura sobretudo no que diz respeito a grupos populares urbanos, segmentos marginalizados do campo e da cidade, etnias em visível processo de apagamento ou desaparecimento, parece um discurso vazio ou, eventualmente, pleno de promessas vãs, já que seu exercício, enquanto integração a algo externo, colaborará na extinção de suas propriedades, linguagens e cultura.

Assim, os esforços mencionados antes, independentemente das boas intenções, estão fadados ao insucesso, a começar pela circunstância de que são recebidos com desconfiança por boa parte de seus destinatários. Que, da sua parte, podem até ter razão, já que o sucesso de empreendimentos como os que embasam PCN, ENEM ou BNCC, talvez coincida com o desenraizamento de suas formas de manifestação, em nome da integração a uma sociedade que deseja recuperar a unificação ideologicamente perdida.

E os COLES, A ALB e AS políticas de leitura?

A identificação da crise de leitura gerou os debates que fomentaram congressos de leitura e educação, por volta das décadas de 1960 e 1970, estendendo-se até os anos 1980. Esse debate acompanhou - e alinhou-se à sua vanguarda - o processo de redemocratização exigido pela sociedade nacional no período, haja vista o tema do COLE de 1981: "Lutas pela Democratização da Leitura no Brasil" (ASSOCIAÇÃO DE LEITURA DO BRASIL, 1981). Reivindicar políticas progressistas de leitura destinadas à população brasileira era também requerer um novo modelo de exercício do poder, de recorte democrático, coletivo e comunitário. 
O êxito ou fracasso do projeto não impede que se admita que, quando, na segunda década do novo milênio, nos referimos à "crise de leitura", estamos lidando com outros conceitos e problemas. Agora, parece-me, é a leitura enquanto concepção que está em crise, porque, a cada vez que utilizamos o termo, temos de ter responder à pergunta: de que leitura estamos falando, o que se passa mesmo nas oportunidades em que nos limitamos à leitura de textos escritos.

Por sua vez, a pergunta não vem sozinha, porque cabe esclarecer o que esperamos - se é que precisamos esperar - da leitura de, por exemplo, textos escritos. Se se tratar de textos literários, podemos manter, na condição de horizonte, o caráter formador valorizado por Antonio Cândido no ensaio seminal, citado antes? Permanece vigente o potencial revolucionário da literatura, alcançado por meio da leitura interpretativa de textos por natureza artísticos, capazes de, através da ficção, estimular e alargar a fantasia?

Os COLES e seu mais ilustre fruto, a Associação de Leitura do Brasil, nasceram no contexto de uma discussão que almejava a redemocratização do país e difundia o ideal de uma leitura emancipadora. Naquele período, porém, não era necessário explicitar o conteúdo dos termos que constituíam o tripé em que se apoiava. Presentemente, trata-se de confirmar e avançar aquela utopia. Que, para se concretizar, requer o alargamento das ideias, valores e meios por intermédio dos quais ela pode se converter em realidade possível.

\section{REFERÊNCIAS BIBLIOGRÁFICAS}

CONGRESSO DE LEITURA DO BRASIL, 3., 1981, Campinas. Resumos. Campinas, SP: ALB, 1981. BENJAMIN, W. Sobre a linguagem em geral e sobre a linguagem humana. In: . Sobre arte, técnica, linguagem e política. Lisboa: Antropos, 1992.

BRASIL. Ministério da Educação. Base Nacional Comum Curricular. Proposta preliminar. 2. ed. revista. Brasília: Ministério da Educação, 2016.

BRASIL. Secretaria de Educação Fundamental. Parâmetros curriculares nacionais: terceiro e quarto ciclos do ensino fundamental: língua portuguesa. Brasília: Secretaria de Educação Fundamental, 1998.

CANDIDO, A. A literatura e a formação do homem. In: . Textos de intervenção. Seleção, apresentações e notas de Vinícius Dantas. São Paulo: Duas Cidades; Ed. 34, 2002.

DARNTON, R. A questão dos livros. São Paulo: Companhia das Letras, 2010.

ECO, U. A memória vegetal. Rio de Janeiro: Record, 2011.

ECO, U.; CARRIÈRE, J-C. - Não contem com o fim do livro. Rio de Janeiro: Record, 2010. 
Os Congressos de Leitura [COLEs] e a crise de leitura, então e agora

GRAFF, H. F. (Ed.). Literacy and Social Development in the West: a Reader. Cambridge: Cambridge University Press, 1981.

HOGGART, R. The Uses of Literacy. London: Pelican, 1977.

ISER, W. The Implied Reader. Patterns of Communication in Prose Fiction from Bunyan to Beckett. Baltimore and London: The Johns Hopkins University Press, 1974. . O ato da leitura: uma teoria do efeito estético. Rio de Janeiro: Editora 34, 1996-99. 2v.

KOZOL, J. A new look at the literacy campaign in Cuba. Harvard Educational Review. Boston, Mass.; Harvard College, v. 48. n. 3, agosto de 1978.

LEAVIS, Q. D. The Fiction and the Reading Public. London: Pelican, 1979.

NUNBERG, G. (Org.). El futuro del libro. Barcelona e Buenos Aires: Paidós, 1998.

OXENHAM, J. Literacy. Writing, reading and the social organization. Boston \& Henley: Routledge \& Kegan Paul, 1980.

SCHNAPP, J. T.; BATTLES, M. The library beyond the book. Cambridge; London: Harvard University

Press, 2014.

ZILBERMAN, R. Fim do livro, fim dos leitores? São Paulo: SENAC, 2001. . Estética da recepção e história da literatura. 3. ed. Porto Alegre: Editora UniRitter, 2015.

\section{SOBRE A AUTORA}

Regina Zilberman é graduada em Letras (Universidade Federal do Rio Grande do Sul), com Doutorado em Romanística (Ruprecht-Karls-Universität - Alemanha) e Pós-doutorados em Letras (University College - Inglaterra; e Brown University -EUA). Atualmente é Professora Adjunta do Instituto de Letras da UFRGS, com atuação no Programa de Pós-Graduação em Letras. Tem experiência na área de Letras, com ênfase em História da Literatura, atuando principalmente nos seguintes temas: leitura, história da literatura, literatura do Rio Grande do Sul, formação do leitor e literatura infantil.

E-mail: regina.zilberman@gmail.com

Recebido em 11 de agosto de 2016 e aprovado em 19 de setembro de 2016. 